\title{
IDENTIFIKASI JENIS ROTAN DI KECAMATAN SELIMBAU KAWASAN TAMAN NASIONAL DANAU SENTARUM
}

\author{
(Identification of Rattan in district Selimbau Danau Sentarum National Park)
}

\author{
Edi Santoso, Fahrizal, Hafiz Ardian \\ Fakultas Kehutanan Universitas Tanjungpura. Jalan Daya Nasional Pontianak 79124 \\ Email: Edi92269@gmail.com
}

\begin{abstract}
Abstrack
Forest is a form of ecosystem containing a stretch of land dominated by trees in a natural environment, that cannot be separated ( forestry law about 41). Rattan is one of forest by products growing naturally in the majority of indonesia, forest and was one of the results forest non wood very large role in meeting the needs of people and foreign exchange revenue for the country, so that immediate action is further as identification of rattan in west borneo, especially in the area a national park lake sentarum. The purpose of this research is to identify of rattan ( palmae) in the lake sentarum national park. Benefits research to provide information about the types contained in selimbau area in a national park lake sentarum to the need for the benefit of operation, preservation, and development. This report is written with uses the method of exploration and a collection of flora cruiser conducted in such a way, in conducting an observation made four lines cruising with long 500 meters while for the distance between the field in accordance with the condition. Fifth the route is track observation $A$, the observation $B$ , the observation $C$, and the observation $D$. A kind of found in domination by the genus Calamus where with a total individual the most ( 4 kind of to 8 individuals), in follow by the genus Daemonorops ( two types of with 7 individuals), the genus Korthalsia (three types of to 4 individuals ), the genus Plectocomiopsis ( two types of with 2 individuals ).
\end{abstract}

Keyword : Danau Sentarum National Park, Identification, Rattan,

\section{PENDAHULUAN}

Kawasan Danau Sentarum merupakan satu dari empat Taman Nasional yang berada di Propinsi Kalimantan Barat yang ditetapkan oleh Menteri Kehutanan dan Perkebunan berdasarkan Surat Keputusan No. 34/Kpts-II/1999 tanggal 4 Pebruari 1999, dengan luas lebih kurang 132.000 ha. Kawasan Danau Sentarum juga merupakan Ramsar Site yang ke-2 di Indonesia setelah Taman Nasional Berbak, yang ditetapkan pada Tahun 1994; Karena selain memiliki ekosistem hutan hujan tropis, Kawasan Danau Sentarum yang ditetapkan juga sebagai Situs Ramsar ini memiliki ekosistem lahan basah danau dan hutan rawa air tawar.

Rotan merupakan salah satu sumber mata pencaharian masyarakat pedesaan dan pengusahaannya yang bersifat padat karya yang dalam arti banyak menyerap tenaga kerja, sehingga jelas kemantapan produksi rotan perlu dipelihara dan ditingkatkan, hal ini tentunya akan berpengaruh terhadap kelestarian rotan, terutama untuk jenis jenis rotan yang komersil yang berlaku di pasaran.

Pemungutan rotan yang secara terus menerus tanpa diikuti dengan peremajaan akan mengancam kelestarian jenis jenis rotan yang ada, sehingga akan menimbulkan kekhawatiran atau berkurangnya potensi 
rotan dimasa yang akan datang. Mengingat jenis rotan yang ada merupakan kekayaan sumber daya yang sangat potensial. Tujuan dari penelitian ini ialah untuk mengidentifikasi jenis rotan (palmae) di kawasan Taman Nasional Danau Sentarum. Manfaat penelitian untuk memberikan informasi mengenai jenis-jenis rotan yang terdapat pada kecamatan Selimbau kawasan Taman Nasional Danau Sentarum kepada pihak yang membutuhkan untuk kepentingan pengusahaan, pelestarian, dan pengembangan.

\section{METODE PENELITIAN Pelaksanaan Penelitian}

Penelitian ini dilaksanakan di daerah kawasan Taman Nasional Danau Sentarum Kabupaten Kapuas Hulu Kalimantan Barat pada bulan mei sampai dengan bulan juni 2016 efektif di lapangan. Penelitian ini dilakukan dengan menggunakan metode eksplorasi dan koleksi flora dilakukan dengan cara jelajah, yaitu menjelajahi setiap sudut suatu lokasi yang dapat mewakili tipe-tipe ekosistem ataupun vegetasi di kawasan yang diteliti (Rugayah, 2004). Dalam pengambilan data di lapangan terbagi atas 4 jalur di kecamatan suhaid di dalam kawasan Taman Nasional Danau Sentarum, dengan panjang 500 meter dan lebar 20 meter (10 meter ke kanan dan 10 meter ke kiri dari sumbu jalur) diletakkan secara sengaja (purposive) dengan mengetahui adanya keberadaan jenis rotan yaitu tempat yang menjadi ciri sebagai habitat dari jenis rotan dalam ekosistem hutan, yang mana masingmasing jalur pengamatan berukuran 500 m x $20 \mathrm{~m}$, sedangkan untuk jarak antar jalur disesuaikan dengan kondisi dilapangan. Semua jenis rotan yang dijumpai pada lokasi penelitian diambil dokumentasi berupa foto beserta contoh herbariumnya. Setiap jenis yang dikoleksi terlebih dahulu diberi nomor koleksi dan dicatat informasi lapangannya.

Contoh jalur pengamatan :

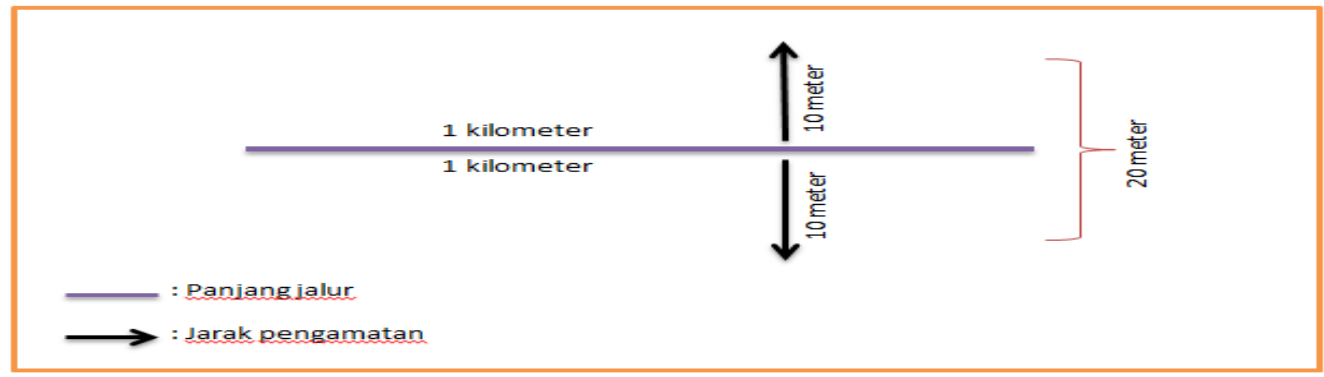

Gambar 1. Jalur pengamatan (Observation Path)

HASIL DAN PEMBAHASAN

Berdasarkan hasil pengamatan dan identifikasi di lapangan pada 4 jalur jelajah di lapangan, kecamatan selimbau di kawasan Taman Nasional Danau
Sentarum (TNDS) yaitu jalur A, B, C, dan $\mathrm{D}$ ditemukan 12 jenis rotan yang tergolong dalam 4 genus. Daftar jenis rotan yang ditemukan pada semua jalur pengamatan.

Tabel 1. Jenis rotan pada jalur pengamatan (Observation Results in the Field) 
JURNAL TENGKAWANG (2017)

Vol. 7 (1) : 57 - 62

\begin{tabular}{llllc}
\hline No & \multicolumn{1}{c}{ Spesies } & \multicolumn{1}{c}{ Genus } & Jalur & Jumlah \\
\hline 1 & Calamus pasphalantus & Calamus & Pengamatan A & 4 \\
& Korthalsia junghuhnii & Korthalsia & & 1 \\
& Daemonorops geniculate & Daemonorops & & 2 \\
\hline 2 & Daemonorops melanochaetes & Daemonorops & Pengamatan B & 3 \\
& Calamus sp & Calamus & & 1 \\
\hline 3 & Daemonorops sabut & Daemonorops & Pengamatan C & 2 \\
& Korthalsia ecinometra & Korthalsia & & 1 \\
& Calamus mucronatus & Calamus & & 1 \\
\hline 4 & Plectocomiopsis sp & Plectocomiopsis & Pengamatan D & 1 \\
& Korthalsia laciniosa & Korthalsia & & 2 \\
& Calamus mattensis & Calamus & & 2 \\
& Plectocomiopsis sp & Plectocomiopsis & & 1 \\
\hline \multicolumn{2}{c}{ Total } & & & 21 \\
\hline
\end{tabular}

Hasil penelitian menunjukan untuk jenis yang ditemukan di dominasi oleh genus Calamus dimana dengan total individu paling banyak dengan 8 individu, di ikuti oleh genus Daemonorops (2 jenis dengan 7 individu), genus Korthalsia (3 jenis dengan 4 individu), genus Plectocomiopsis (2 jenis dengan 2 individu).

Keanekaragaman jenis yang terdapat pada suatu hutan disebabkan oleh perpaduan beberapa faktor lingkungan seperti topografi, ketinggian tempat, jenis tanah, iklim dan pasokan air, terutama curah hujan dan kelembapan hutan (Randi, 2011). Kawasan Danau Sentarum ini relatif rendah, dengan ketinggian antara 25600 mdpl dengan rata-rata ketinggian \pm $35 \mathrm{mdpl}$ di atas permukaan laut. Untuk ketinggian topografi di atas $35 \mathrm{mdpl}$ masuk pada kawasan perbukitan seperti Bukit Tekenang, Bukit Menyukung, Bukit Melingkung, Bukit Selaseh, Bukit Semujan, dan Bukit Segerat. ( RIP Danau Sentarum, 2002 ).
Secara umum rotan tumbuh di daerah hutan hujan tropis baik pada hutan primer maupun hutan sekunder sampai pada ketinggian 1500 meter dpl. Genus Korthalsia yaitu Korthalsia Ecinometra. Jenis ini di jumpai lokasi pengamatan dari tempat yang terbuka dan bersemak, dengan kanopi hutan yang cukup rapat pada ketinggian 400 mdpl. Jenis $K$. echinometra tersebar luas dan sangat toleran terhadap gangguan dan kondisi yang kurang menguntungkan untuk rotan jenis lain. Pada saat pengamatan dilapangan tidak ditemukan jenis ini di tempat-tempat yang tertutup, jenis dapat tumbuh dengan intensitas cahaya matahari tinggi pada hutan primer. memiliki ciri yaitu tumbuh berumpun memanjat dan bercabang pada kanopy hutan sampai ketinggian 30 meter. (Jasni, 2012).

Sedangkan untuk jenis Korthalsia junghuhnii dan Korthalsia laciniosa, ditemukan dataran rendah perbukitan ditepian aliran sungai, dimana kondisi lantai hutan yang berpasir dan bebatuan pada ketinggian 600 meter dpl. Untuk jenis Korthalsia Laciniosa memilki ciri 
yaitu Rotan ramping tumbuh berumpun bercabang tinggi mencapai 50 meter. Batang berbentuk bulat diameter dengan pelepah mencapai $40 \mathrm{~mm}$. pada jenis KorthalsiaJunghuhnii memiliki ciri yaitu jenis ini tumbuh berumpun dengan lebat dan sering bercabang tinggi dalam tajuk hutan sehingga mengakibatkan belitan besar, batang mencapai panjang $8 \mathrm{~m}$.

Selain genus Korthalsia, genus yang paling banyak dijumpai pada lokasi penelitian adalah genus Calamus yaitu Calamus geminiflorus Griff \& Calamus pasphalantus ke dua jenis ini di jumpai pada daerah-daerah yang lembab di sekitar aliran sungai dan pada tebing-tebing di pinggir sungai dengan ketinggian 25-320 mdpl. Dimana untuk jenis CalamusPasphalantus merupakan yang paling sering di jumpai, dikarenakan jalur-jalur pengamatan yang dibuat merupakan habitat dari jenis ini. genus ini dapat tumbuh dari daerah rendah sampai daerah yang cukup tinggi, tetapi jenis ini lebih banyak ditemukan didaerah yang cukup ternaungi dan disepanjang daerah pinggiran sungai. Ciri umum untuk mengenal genus ini adalah batang yang berukusan besar, hidup berumpun dan memanjat. Sedangkan untuk jenis CalamusGeminiflorus memilki ciri yaitu Rotan, memanjat sampai $30 \mathrm{~m}$ tingginya. Diameter batang dengan pelepah daun 35 tumbuh berumpun. Tempat tumbuh Calamusgeminiflora di hutan primer dipterokarpa dataran rendah, pada berbagai jenis tanah, pada ketinggian sampai 600 meter di atas permukaan laut. Namun ada beberapa genus yang terdapat pada lokasi penelitian yaitu genus Calamus yang terdiri dari dua jenis ialah Calamus Sp. Rotan ini tumbuh soliter (tunggal) atau tidak berumpun. Rotan ini mempunyai jangkauan merambat yang cukup baik karena batangnya bisa memiliki panjang sampai $30 \mathrm{~m}$, yang tumbuh didataran rendah perbukitan.

Adapun jenis CalamusMattenensis Becc yang tumbuh didataran perbukitan dengan kondisi lantai hutan yang berpasir dan bebatuan. Memiliki ciri umum yaitu hidup dengan cara membentuk suatu rumpun yang satu atau dua dari batangnya menjalar dan memanjat. Tempat tumbuhnya tersebar didataran rendah. Selain itu rotan ini tumbuh didaerah semak belukar yang beriklim basah. Batang rotan ini dapat mencapai tinggi lebih dari $20 \mathrm{~m}$, dengan diameter batangnya $3 \mathrm{~cm}$ dan ruas batang mencapai $30 \mathrm{~cm}$ atau lebih. Batangnya berwarna coklat kemerah merahan jika sudah kering

Genus Daemonorops merupakan genus dengan individu terbanyak ketiga yang dijumpai dilokasi penelitian jenis yang ditemukan yaitu Daemonorops melanochaetes dan Daemonoropssabut, kedua jenis ini dijumpai pada daerah aliran sungai, tepian-tepian sungai dari tempat yang lembab sampai pada tempat-tempat terbuka dengan cahaya matahari penuh. Tetapi untuk jenis Daemonorops Sabut pada saat penelitian lebih sedikit dijumpai ditepian sungai atau daerah berawa. Ciri dari jenis mudah untuk membedakan dari jenis yang lain yaitu tumbuh berumpun, memanjat sampai tinggi 40 
meter, ditumbuhi kolar-kolar berukuran $10 \mathrm{~mm}$, ujung kolar ditumbuhi rambut seperti duri berwarna coklat kehitaman. Untuk jenis Daemonorops melanochaetes memiliki ciri umum yaitu tumbuh berumpun, memanjat sampai tinggi 12 meter. Batang berbentuk bulat, diameter dengan pelepah daun berwarna hijau kecoklatan, ditumbuhi duri rapat berwarna hitam, panjang duri $2-3,5$ $\mathrm{cm}$, mulut pelepah daun dikelilingi duri berwarna hitam panjangnya sampai 5 $\mathrm{cm}$, ditumbuhi duri hitam dibagian bawah. Jenis ini banyak tumbuh ditepian-tepian sungai.

Adapun satu jenis dari genus yang sama ialah Daemonorops sp memilki ciri rotan tumbuh berumpun, memanjat sampai pada ketinggian $15 \mathrm{~m}$. batang berbentuk bulat, diameter dengan pelepah $30 \mathrm{~mm}$. pelepah daun memilki lutut, berwarna hijau mengkilap, ketika masih muda ditumbuhi dengan indumentum, warna coklat, ditumbuhi duri berwarna hitam, tersusun melingkar tidak teratur. Jenis juga banyak dijumpai pada lokasi penelitian yang sering terdapat pada daerah tepian sungai.

Genus Plectocomiopsis yang ditemukan terdiri dari 2 jenis yaitu Plectocomiopsis sp dengan masingmasing 1 individu. Tempat tumbuh genus Pletocomiopsis ini saat penelitian genus ini ditemukan ditepian aliran sungai dengan lantai hutan yang berpasir dan bebatuan pada daerahdaerah yang lembab dengan tajuk pohon yang rapat dengan sedikit sekali cahaya matahari yang masuk. Jenis ini umumnya tumbuh dihutan dataran rendah yang selalu hijau dan hutan yang basah atau lembab.

\section{KESIMPULAN DAN SARAN}

\section{Kesimpulan}

Berdasarkan penelitian Identifikasi Jenis Rotan di Kecamatan Selimbau Kawasan Taman Nasional Danau Sentarum Kabupaten Kapuas Hulu Provinsi Kalimantan Barat dapat di simpulkan bahwa :

1. Ditemukan sebanyak 12 jenis dengan 4 genus berbeda dengan total keseluruhan 21 individu.

2. Adapun jenis-jenis rotan tersebut ialah Rotan duri lembah (Korthalsia Ecinometra), Rotan duri nanga (Daemonorops geniculate mart), Rotan duri pelanduk (Korthalsia junghuhnii), rotan duri tapah (Calamus pasphalantus), Rotan duri angkut (Calamus sp), Rotan antu (Daemonorops melanochaetes), Rotan duri dan (Plectocomiopsis sp), Rotan duri pukul (tunggal), (Calamus mucronatus), Rotan duri seluang (Plectocomiopsis sp), Rotan duri seru (Korthalsia laciniosa), Rotan kelian (Daemonorops sabut), Rotan maram (Calamus mattensis becc).

3. Rotan yang ditemukan sebanyak 12 jenis 4 diantaranya belum teridentifikasi sampai ke tingkat spesies yaitu Calamus $s p$, Daemonorops sp, dan dua jenis Plectocomiopsis sp dikarenakan kurangnya literature tentang kunci identifikasi rotan.

4. jenis yang ditemukan di dominasi oleh genus Calamus dimana dengan 
total individu paling banyak dengan 8 individu, di ikuti oleh genus Daemonorops (2 jenis dengan 7 individu), genus Korthalsia (3 jenis dengan 4 individu), genus Plectocomiopsis (2 jenis dengan 2 individu).

\section{Saran}

1. Untuk mengetahui tentang identifikasi jenis rotan, perlu diakukan penelitian lebih lanjut khususnya di Kawasan Taman Nasional Danau Sentarum Kabupaten Kapuas Hulu Provinsi Kalimantan Barat.

2. Pentingnya usaha untuk menjaga dan mempertahankan kelestarian sumber daya alam yang ada pada daerah Kecamatan Selimbau Kawasan Taman Nasional Danau Sentarum Kabupaten Kapuas Hulu Provinsi Kalimantan Barat khusunya jenis jenis rotan, maka diharapkan pada seluruh instansi terkait agar dapat memberikan perhatian yang sungguh-sungguh terhadap pelestarian sumber daya alam ini.

3. Perlu adanya peremajaan rotan agar jenis-jenis yang ada tidak punah dan dapat terus dilestarikan.

\section{DAFTAR PUSTAKA}

Anonim, 2002. Penyusunn Rencana Induk Pengelolaan Danau Sentarum Kapuas Hulu, Kalimantan Barat

Jasni, 2012. Atlas Rotan Indonesia Jilid 3 Pusat Penelitian dan Pengembangan Ketenikan Kehutanan dan Pengolahan Hasil Hutan. Badan Penelitian dan Pengembangan Kehutanan Kementrian Kehutanan. Bogor
Randi, A. 2011. Identifikasi Jenis-jenis Pohon Penyusun Vegetasi Gambut Taman Nasional Danau Sentarum Kabupaten Kapuas Hulu. [skripsi]: Fakultas Kehutanan, Universitas Tanjungpura. Pontianak

Rugayah, A. Retnowati, F.I. Windadri \& A. Hidayat. 2004. Pengumpulan data taksonomi. Pedoman pengumpulan data keanekaragaman flora. Pusat Penelitian Biologi, Bogor Indonesia.

Undang-Undang Kehutanan, 41. 1999 Tentang Kehutanan. Indonesia 